\title{
TEORIA DAS NECESSIDADES HUMANAS BÁSICAS - UM MARCO INDELÉVEL NA ENFERMAGEM BRASILEIRA*
}

\author{
Tamara Iwanow Cianciarullo **
}

CIANCIARULLO, T.W. Teoria das necessidades humanas básicas - um marco indelével na enfermagem brasileira. Rcv. Esc. Enf. USP, São Paulo, 21 (no especial): 100-107, 1987.

As teorias de enfermagem têm sido freqüentemente visualizadas num enfoque dicotômico do existir, não existir; do ser, não ser e da possibilidade ou não de sua utilização na prática.

No Brasil, em estudo realizado por ANGERAMI e BOEMER, em 1984, foi verificado que cerca de $90 \%$ das escolas que responderam a um questionário, afirmaram ministrar o tema "Teorias de Enfermagem". Destas 35 escolas, 30 referiram ensinar a Teoria das Necessidades Humanas Básicas, ressaltando-se que, com raras exceções, a aplicação de teorias na prática restringia-se ao uso do processo de Enfermagem, proposta por Horta.

Possuir um corpo de conhecimentos próprio e uma prática independente e autônoma, parece representar as nossas mais elevadas aspirações.

$\mathrm{Na}$ realidade, no entanto, essas aspirações diluem-se nas chamadas teorias que, para muitos céticos, parecem um amontoado de palavras que subtraem a "essência de fazer enfermagem", relegando assim a teoria ao campo acadêmico, como um exercício intra-mural, ratificando a expressão "na prática a teoria é outra".

Claro está que as teorias deveriam ter um papel mais importante do que apenas fomentar visões intelectuais de como as enfermeiras deveriam fazer a enfermagem.

$\mathrm{Na}$ nossa realidade, as teorias geralmente aceitas são aquelas que provêm de centros de enfermagem mais avançados, caracterizando nossa dependência tecnológica neste âmbito. Embora se afirme que os conhecimentos resultantes do "fazer enfermagem" sejam transculturais, há que se perceber que a essência do ser-enfermeiro e do ser-cliente, numa relação de interdependência, certamente influenciará o ser-enfermagem, produzindo ações de enfermagem específicas em determinados contextos culturais.

\footnotetext{
* Tema oficial.

* Professor Assistente Doutor do Departamento de Enfermagem Médico-Cirúrgica da Brscola de Enfermagem da USP.
} 
Apresenta-se ai, o credo de Wanda de Aguiar Horta, que nos anos sessenta, estudando e ensinando as propostas teóricas iniciais das autoras americanas, passa a "pensar" sobre a enfermagem. E, é neste contexto que surgem as verdadeiras "novas dimensões" brasileiras de enfermagem: do encontro do Ser-enfermeiro, com o Ser-cliente, resultante das percepções e ações que levam a uma transação - neste momento surge o Ser-Enfermagem. Um ser abstrato que tem, na concepção de Wanda de Aguiar Horta, como objeto a assistência às necessidades humanas no ciclo saúde-enfermidade em qualquer fase do ciclo vital.

Inicia-se, neste contexto, a teoria das Necessidades Humanas Básicas da enfermeira Wanda de Aguiar Horta.

\section{ESTRUTURA PROPOSTA PARA A ANÁLISE DA TEORIA}

Destacados autores têm se empenhado em subsidiar as enfermeiras na análise, avaliação e crítica de teorias, no sentido de facilitar a compreensão e possibilitar sua utilização na prática, no ensino e na pesquisa.

Dentre os mais recentes autores, destacam-se STEVENS (1984), MELEIS (1985) e CHINN (1983) que, usando estudos apresentados por seus antecessores, desenvolveram propostas de modelos de análise que apresentam as relações entre as funções e a estrutura das teorias a serem analisadas.

MELEIS (1985) afirma que a enfermagem é um campo humanístico e científico, com âmbito de ação delimitado, envolvendo seres humanos e lidando com um conjunto de variáveis complexas, que determinam a necessidade de um conjunto de critérios, para a avaliação da teoria, que leve em consideração a complexidade e o contexto desta teoria.

O modelo apresentado por MELEIS (1985), caracteriza-se pelo enfoque descritivo, analítico e avaliativo.

O enfoque descritivo inicia-se pela determinação da questão central efetuada pelo teorista. Alguns autores afirmam que nem sempre os teoristas conseguem apresentar o seu fim último.

A questão central na teoria proposta por Wanda de Aguiar Horta é o atendimento das necessidades humanas básicas, apresentado pela autora a partir dos trabalhos de Maslow (teoria da motivação humana) e do padre João Mohana que, juntados à sua filosofia de enfermagem, expresso no primeiro capítulo do seu livro, constitui o conjunto dos pressupostos de sua teoria.

Assim, a sua busca da Verdade, do Bem e do Belo, pressupõe uma filosofia unificada para a enfermagem, fundamentando as bases para o seu desenvolvimento; expõe a realidade de enfermagem sob a forma de Seres: o Ser-Enfermeiro, o Ser-Cliente, o Ser-Enfermagem. Os dois primeiros são humanos e mutuamente exclusivos quando isolados. $O$ Ser-Enfermeiro, afirma Horta, é um ser humano, com todas as suas 
dimensōes, potencialidades e restrições, alegrias e frustrações, aberto para o futuro, para a vida e nela engajado pelo compromisso assumido com a enfermagem. Este compromisso envolve a aprendizagem cognitiva, afetiva e motora, visando a sua formação como enfermeiro, quando a sociedade lhe outorga o direito de "cuidar de gente".

Percebe-se aí claramente a influência da "filosofia do compromisso" de VAILLOT (1966), muito utilizada por HORTA em suas aulas no curso de mestrado na USP.

A expressão criada por Horta, nos anos sessenta, para definir o Ser-Enfermeiro: "gente que cuida de gente", foi utilizado por uma empresa de medicina de grupo, que a emprega hoje, como "slogan" na midia, identificando suas características humanitárias para o público.

O Ser-cliente na concepção de Horta, tanto pode ser um indivíduo, uma familia ou uma comunidade, que necessita de cuidados de outros seres humanos habilitados para este tipo de ação.

O Ser-Enfermagem é um ser abstrato, que tem como objeto assistir as necessidades humanas básicas que, neste contexto, caracterizam-se como entes da enfermagem. Os entes da enfermagem, descritos, explicados, relacionados entre si e passiveis de serem submetidos a predições, formalizam nesta teoria a ciência de enfermagem, na concepção de Horta.

As necessidades humanas básicas, por sua vez, são estados de tensão, conscientes ou inconscientes, resultantes dos desequilíbrios homeodinâmicos dos fenômenos vitais. Em estados de equilíbrio dinâmico, afirma Horta, as necessidades não se manifestam, permanecendo em estado latente. Assim, estados de equilíbrio correspondem à fase de latência das necessidades humanas básicas, e os estados de desequilíbrio correspondem às manifestações das alterações das necessidades humanas básicas. A intensidade da manifestação, por sua vez, depende do desequilíbrio instalado. Entende-se por manifestação da alteração nas necessidades humanas básicas, a condição ou situação apresentada pelo indivíduo, familia ou comunidade que exige uma resolução para voltar ao estado de equilíbrio. Esta manifestação pode ser aparente ou inaparente, consciente ou inconsciente e verbalizada ou não. A manifestação de alterações em uma necessidade humana básica, que exija assistência de enfermagem, recebe o nome de problemas de enfermagem. Como exemplo, podemos citar o trabalho de GONÇALVES (1979), sobre segurança emocional, em que a autora considera a ansiedade, tensão, angústia, desconfiança, medo, raiva e temor, como manifestações desagradáveis de experiência emocional e que, conseqüentemente, são considerados como problema de enfermagem.

As necessidades humanas básicas, em sendo comuns a todos os seres humanos, são universais. Objetivando facilitar o estudo das necessidades humanas básicas, Horta adotou o sistema de classificação preconizado por MOHANA: 
necessidades de nivel psicobiológico

necessidades de nível psicossocial

necessidades de nivel psicoespiritual

Todas estas necessidades apresentam-se inter-relacionadas, fazendo parte de um todo indivisivel, extrapolando os limites de simples somatória das partes. Estas inter-relações apresentam um gradiente de ligações, mais ou menos intenso, como resultado das manifestações associadas a desequilíbrios causados por falta ou por excesso de atendimento. Assim, CASTELLANOS (1978), estudando a necessidade humana básica de liberdade, considera o amor, a comunicação, a segurança, a religião, a locomoção, a auto-realização e a gregária, como aquelas que maior envolvimento apresentam com a liberdade. SILVEIRA (1976), estudando locomoção e mobilidade, também refere outras necessidades relacionadas em maior ou menor grau a estas.

Horta nunca escondeu a complexidade do estudo a que se propôs, esperando sempre que outros se engajassem neste desafio, estudando as manifestações das álterações das necessidades humanas básicas, no sentido de criar a ciéncia de enfermagem.

Alguns estudiosos no Brasil referem-se à inespecificidade de delimitação do papel do enfermeiro no atendimento das Necessidades Humanas Básicas, proposto por Horta.

Há que se considerar que, em sendo a enfermagem uma área de conhecimento que se utiliza de conhecimento de outras áreas, combinados entre si, certamente, gerará uma nova área de conhecimento, que Leininger chamou de "Ciência do cuidado" - dando origem aos termos "assistência cuidativa".

Não seria este o caminho desejado por Horta?

Ao analisarmos outras propostas teóricas, verificamos que em não se criando terminologias específicas para designar a ação substantiva da enfermagem, como o fez LEININGER, fica muito difícil descriminar a ação específica da enfermeira. Assim, à luz da realidade vigente, este fato não parece prejudicar a teoria como um todo, orientando, no entanto, os futuros pesquisadores da teoria das Necessidades Humanas Básicas, em suas validações.

A partir desta proposta eminentemente teórica, Horta avança para a prática desejável, usando terminologias e conceitos já identificados pelos enfermeiros brasileiros para explicar a função do enfermeiro. Caracteriza três campos ou áreas de ação distintas: área específica, de interdependência e social.

Horta, em sua concepção específica da enfermagem, mantém um limite entre o assistir o ser humano no atendimento de suas necessidades básicas e ensinar o autocuidado e a função de manter, promover e recuperar a saúde. Esta última, visualizada como a atividade de 
enfermeira na equipe de saúde. Percebem-se claramente os limiares intrinsecos destas ações, propostas pela própria autora, por meio da representação gráfica apresentada em sua obra. A abordagem dada por Horta apresenta um novo centro de interesse a ser desenvolvido por pesquisadores na área, na tentativa de buscar alternativas da classificação das funções da enfermeira, iniciando a discriminação operacional destas ações num nivel teórico.

Implementando sua proposta teórica, Horta chega ao método de atuação da enfermagem chamado: Processo de Enfermagem. Diferencia a sua proposta das demais propostas da época, por meio da apresentação de seis fases, representadas por um hexágono, chamado atualmente "Hexágono de Horta".

Algumas destas fases identificam-se com os conceitos de outras teoristas, mas outras fazem parte exclusiva do seu contexto teórico. $\mathrm{E}$ todos estes, só poderão ser validados por meio de pesquisas operacionais, extrapolando o âmbito de análise teórica e de questionamentos mentais. Neste ponto ,necessitamos de informação empírica consistente, tendo em vista que os passos ou fases referem-se à atuação da enfermeira e conseqüiente operacionalização dos conceitos elaborados e propostos.

Há que se destacar ainda que, dentre os dez autores de teorias que tiveram seus modelos analisados por MELEIS, três apenas, conseguiram estabelecer o âmbito dos 12 conceitos considerados pela autora. Apresentamos aqui os mesmos conceitos identificados na teoria de Horta.

As proposições explícitas da autora aparecem claramente estruturadas em relação à assistência de enfermagem, função da enfermeira e âmbito da ciência de enfermagem.

Os conceitos explícitos e implícitos têm ressonância teórica, estrutura sistematizada e inter-relacionada, apesar de sua simplicidade.

\section{ORIGENS PARADIGMATICAS}

Horta usou em sua teoria dois paradigmas fundamentais: o de Maslow e o de Mohama. Usando sua criatividade e o seu saber, associou as duas propostas num sistema de classificação próprio, que mostra claramente a sua linha de pensamento. Outras teoristas também influenciaram a sua teoria: McDowell (homeostasia), Levine (holísitica), Roy (adaptação), King (percepção, transação e interação) e Rogers (homem no tempo e no espaço).

$O$ resultado final destas influências centraliza o processo de assistência a ser utilizado pela enfermeira no atendimento das Necessidades Humanas Básicas.

Parece-nos que a teoria apresentada por Horta teria um poder prescritivo muito maior, se nós, enfermeiras, nos últimos 15 anos, tivés- 
semos nos preocupado com a estrutura do saber fazer enfermagem, ao invés da estrutura como um simples método.

\section{DIMENSÕES INTERNAS}

Horta inicia a construção da sua teoria num alto nivel de abstração, fundamentando-se nos valores pessoais e profissionais. A seguir, percorre um caminho lógico dedutivo, baseando-se nos paradigmas já citados.

Estabeleceu um sistema de relações simples entre os conceitos abstratos e concretos, desenvolvendo um modelo operacional, centrado no como se deveria fazer enfermagem.

Propõe uma teoria de amplo alcance, visualizada por meio das suas proposições e principios que orientam as ações de enfermagem e caracterizam a sua clientela.

A teoria indica um caminho para o julgamento clínico de enfermagem, determinando, categorizando e priorisando ações a serem implementadas, permitindo uma prospecção dos resultados dessa ação, se for estudada cuidadosamente. Além desse aspecto, proporciona subsídios para a avaliação da qualidade da assistência de enfermagem.

A operacionalização da teoria é explícita e está concatenada, porém de construção complexa no que se refere ao diagnóstico e prognóstico, exigindo, como a própria autora refere em sua obra, a inclusão destes modelos na prática, a titulo experimental para a sua validação.

Outro aspecto a ser destacado é a importância da validação de nivel de dependência/independência, em relação à capacidade de auto-cuidado do cliente.

O contexto utilizado pela autora é abrangente, visto que o conhecimento relativo às Necessidades Humanas Básicas ocorre no equilíbrio e no desequilibrio das suas manifestações, estabelecendo ainda um controle sobre os resultados das açōes propostas (evolução e prognóstico).

É uma teoria operacional, segundo STEVENS (1976), por estar organizada ao redor de métodos de intervenção, no caso, o processo de enfermagem.

\section{A TEORISTA}

Estrutura proposta para a crítica

A parte operacional da teoria das Necessidades Humanas Básicas tem sido utilizada na prática, eventual ou rotineiramente, e foi incorporada oficialmente nos serviços do INAMPS, como base das ações da enfermeira.

No ensino, grande número de programas em cursos de graduação e pós-graduação utilizam sua teoria como marco conceitual. 
Devido ainda ao precário desenvolvimento do hábito de nossas enfermeiras de publicarem suas experiências práticas, principalmente quando não são bem sucedidas, em primeira instância, não podemos estabelecer a amplitude da utilização da teoria em âmbito nacional.

Podemos, no entanto, afirmar que os estudos de Horta influenciaram a prática, o ensino, a pesquisa e a administração da assistência de enfermagem.

A própria autora sempre enfatizou a importância de se testar a teoria em contextos culturais diferenciados, de modo a fornecer subsídios para o seu desenvolvimento.

$\mathrm{Na}$ pesquisa, a teoria proposta por Horta, foi utilizada inúmeras vezes, em partes ou como um todo.

Há que se destacar que muitos destes estudos situam-se ao nível de identificação das manifestações das Necessidades Humanas Básicas, talvez pela limitação de conhecimento da teoria pelos próprios pesquisadores.

Apesar de não ter tido tempo para rever e aprofundar sua teoria, como muitos outros autores fizeram, Horta deixou um conjunto importante de conhecimentos a serem testados e validados em benefício de fazer e saber enfermagem, que pelo nosso ritmo, certamente, não será esgotado nos próximos vinte anos.

Em sendo uma teoria de abordagem ampla, é considerada como um suporte para a pesquisa, para assistência e para a administração. Não percebemos restrição à sua aplicação na prática e no ensino, a não ser pelas nossas próprias limitações, ligadas à enfermagem de um país em desenvolvimento, com poucos recursos para as pesquisas e com restrito âmbito da decisão no campo da saúde do povo brasileiro.

A complexidade em termos da aplicação da teoria, talvez se situe a nivel da busca de amplitude e profundidade dos seus conceitos, visto que teriamos que seguir o seu caminho paradigmático, para dominar 0 suporte teórico proposto por Horta.

\section{COMPONENTES EXTERNOS DA TEORIA}

A teoria pode parecer incongruente com a maior parte dos atuais valores dos enfermeiros, mas congruente com os valores emergentes que demonstram preocupação com a independência do Ser-Enfermagem, com a autonomia das decisões e das ações do enfermeiro e principalmente com a necessidade de se sistematizar estas ações de modo a possibilitar uma avaliação da qualidade dos resultados do seu trabalho.

E uma teoria transcultural, visto que as Necessidades Humanas Básicas são universais, variando apenas nas suas manifestações e no seu atendimento.

Se conceitos, definições, descriçōes, explanações, dimensōes e outros caracteres de uma abordagem teórica parecem não satisfazer alguns 
autores e estudiosos, devemos lamentar tão somente a inexistência do compromisso grupal no âmbito da enfermagem brasileira.Não buscamos formar grupos ou equipes interessadas em crescer ou fazer a enfermagem crescer. Em nossa essência, somos apenas "indivíduos", usamos os trabalhos daqueles que pensam e estudam por nós, mas pouco contribuimos num sistema de referência e contra-referência de conhecimentos, tão importantes para o desenvolvimento do saber e da ciência da enfermagem.

Muitas são as falhas que podemos encontrar em qualquer trabalho, mas em contrapartida pouco é o que "podemos" acrescentar, dentro das nossas próprias limitações de saber fazer teoria.

Analisar a profundidade na abordagem de alguns conceitos teóricos parece-nos pouco oportuno, visto que existe explicitado no texto de concepção teórica de Horta o marco referencial, no qual ela se baseou. Isto, deve servir de estímulo na busca de subsídios para futuros trabalhos sobre sua teoria, no sentido de contribuir para o saber da enfermagem de forma endógena, crescendo e fazendo crescer a enfermagem brasileira. 